\title{
Emerging biomarkers of congenital heart diseases and disorders
}

\begin{abstract}
Present review aims to discuss new emerging biomarkers that could facilitate authentic and fast diagnosis of congenital heart diseases. The population of congenital heart disease patients is increasing regularly and serious complications in adults are also enormously exceeding in comparison to children. Most of these congenital defects are un-curable and becoming challenging to treat. However, for predicting the prognosis of patient's different types of biomarkers i.e. hemodynamic, physiological, genetic, molecular, immunological, clinical and therapeutic biomarkers are explained. For sequential assessment of major structural and functional defects in CHD (congenital heart diseases) patients various bioassays and scientific methods are used to integrate defects with symptoms to find therapeutic decisions, targets and goals. This article tries to explore therapeutic options and solutions of CHD on the basis of emerging biomarkers and assess the need to advent new potential authentic biomarkers.
\end{abstract}

Keywords: congenital heart disease, cardiac abnormalities, cardiac, diagnostic and therapeutic biomarkers
Volume I Issue 3 - 2016

Ravi Kant Upadhyay
Department of Zoology, DDU Gorakhpur University, India

Correspondence: Ravi Kant Upadhyay, Department of Zoology, DDU Gorakhpur University, Gorakhpur, 273009, U.P, India,Email rkupadhya@yahoo.com

Received: May 27, 2016 | Published: August 02, 2016

\section{Introduction}

Congenital heart diseases are substantially appeared before or after birth. There are two important disease categories which are commonly appeared in after birth vascular, congenital heart disease. Right ventricular hypertrophy is one of important congenital heart disease. These abnormalities are related to either structure or function of heart and also found associated to cardiovascular system. In principle these are recognizable in early life and are observed in 7-12 of every 1000 live births. But it is of all the trivial lesions which are recognized in early child hood. During infancy 50-60 per cent of these patients need medical and surgical help, among total non-treated patients only 10-15 per cent get survive without surgery to adolescence and adult life. These are known as natural survivors whose congenital defects or disease modify with the time and face post natal changes and remain abnormal. Prevalence of these diseases show lower child survival index that display basal infant and child mortality under the age of 5 years. Besides, children congenital heart diseases, adult congenital heart diseases are reported to increasing alarmingly. Though there are hundreds of congenital defects and few of them come in rare categories.

Tetralogy of Fallot ${ }^{1}$ is, neonatal lupus or congenital heart block a significant health problems whose pathogenesis is quite complex. ${ }^{2}$ Similarly, end-stage heart failure and abnormalities of bicuspid aortic valve are also congenital ${ }^{3}$ (Table 1 ). Prominent intrapulmonary anastomotic vessels or bronchopulmonary shunt vessels is also reported in lungs from infants with fatal congenital diaphragmatic hernia Down syndrome is the most common viable chromosomal disorder with intellectual impairment and several other developmental abnormalities. Forty to fifty percent of newborns with down syndrome have some form of congenital heart defects. ${ }^{4}$ Endocardial fibroelastosis is a unique form of fibrosis, which forms a de novo sub-endocardial tissue layer encapsulating the myocardium and stunting its growth, is typically associated with congenital heart diseases of heterogeneous origin, such as hypoplastic left heart syndrome. ${ }^{5}$
Pulmonary arterial hypertension is a serious complication of adult congenital heart disease associated with systemic-to-pulmonary shunts and shows markedly increased morbidity and mortality in infants. ${ }^{6}$ Although early shunt closure restricts development of pulmonary arterial hypertension, but patients remain at risk even after repair. Hyperuricaemia is associated with traditional cardiovascular risk factors such as type 2 diabetes or dyslipidaemia and shows higher mortality (Table 2). An aneurysm is a local dilatation of a vessel wall which is $>50 \%$ of its original diameter. Aortic aneurysms are among the most challenging to treat. ${ }^{7}$ Similarly, early stage heart failure in adults is a severe congenital heart disease remains elusive in diagnosis (Table 1). Many ACHD ( Adult Congenital Heart Disease) patients seem well-compensated owing to chronic physical and psychological adaptations, but these remain abnormal even after post surgery they report stable health and good quality of life. ${ }^{8}$

Biomarkers are important tools which are used for assessment of disorder or disease, its clinical diagnosis, prognosis, recurrence and possible therapeutics. These are indicators of a biological state and can detect alterations in the constituents of tissues or body fluids more promptly and accurately. Before treatment establishment of cause of deformity and its types should be established to recognize high risk groups among patients. Biomarkers are used to explore specific defects, and assist in management of postoperative cardiac patients facing congenital heart diseases. ${ }^{9}$ However, by measuring levels of important molecules in patient's tissue fluids clinicians can analyze and interpret results to identify congenital heart disease and its possible therapeutics. ${ }^{10}$ For example to establish left ventricular systolic dysfunction a test with LR + and LR- negative is used to predict the level of risk. Similarly tests based on urine N-terminal pro-BNP (brain natriuretic peptide) (N-BNP) test is also followed by a plasma N-BNP test that can facilitate screening for asymptomatic left ventricular systolic dysfunction in CHD patients. Mainly estimations of bio-molecules in body fluids are used for predicting the prognosis of patients with heart failure, pulmonary hypertension and dilated 
cardiomyopathy. This article presents the most relevant developments taken place in congenital heart disease, clinical cardiology, and heart failure and transplants. For prenatal and postnatal diagnosis of congenital defects following biomarkers are discussed.

Table I Showing important congenital heart diseases in children and adults

\begin{tabular}{|c|c|c|c|}
\hline \multicolumn{2}{|l|}{ CHD Type } & \multicolumn{2}{|l|}{ ACHD Type } \\
\hline \multicolumn{2}{|c|}{ Defects of cardiovasular and neurological system } & \multicolumn{2}{|c|}{ Defects of cardiovascular and neurological system } \\
\hline Cardiac defects & $\begin{array}{l}\text { Systemic and pulmonary blood } \\
\text { supply }\end{array}$ & Mature structural defects & Abnormality \\
\hline Left or right atrial isomerism & $\begin{array}{l}\text { Bilateral trilobed lungs with short } \\
\text { epithelial bronchi }\end{array}$ & $\begin{array}{l}\text { Multiple spleens arrive } \\
\text { major congenital diseases }\end{array}$ & Cereberllar abscess \\
\hline Anteroventricular discordance & Endocardial fibrosis & Polycythaemia & Central cyanosis \\
\hline Ambigious atrioventricular connections & $\begin{array}{l}\text { Absent pulmonary valves defects in } \\
\text { pulmonary venus drainage }\end{array}$ & Gout & Fallot's tetralogy \\
\hline Atrioventricular septal defects & $\begin{array}{l}\text { Classic transposition of great } \\
\text { arteries, }\end{array}$ & Acute Renal problems & $\begin{array}{l}\text { Acyanotic congenital heart } \\
\text { disease in adults, }\end{array}$ \\
\hline Superior sinus venosus defect, & Corrected malposition & Skin sepsis, & $\begin{array}{l}\text { Left ventricular hypertrophy } \\
\text { and central cyanosis, }\end{array}$ \\
\hline Secundum defect, & Double out flow right ventricle & Thrombosis and bleeding & $\begin{array}{l}\text { Abnormal right ventricle and } \\
\text { shunt reversal at atrial level }\end{array}$ \\
\hline Inferior sinus venous defect & Shunt reversal at atrial level & Relative anemia & Spina bifida \\
\hline Anomalies of atrioventricular valves & Valves of outflow tract may calcify & Bleeding gums & Cleft lip/palate \\
\hline Tetralogy of fallot & Endocardial fibroelastosis & Unroofed coronary sinus & Hypertesnion \\
\hline $\begin{array}{l}\text { Plastering across of tricuspid valve } \\
\text { tissue }\end{array}$ & Hypoplastic left heartsyndrome & $\begin{array}{l}\text { Pulmonary arterial } \\
\text { stenoses }\end{array}$ & Loss of memory \\
\hline Superior sinus venosus defect & $\begin{array}{l}\text { Mitral regurgitation, left atrial } \\
\text { obstruction }\end{array}$ & Aortic stenosis & Mongolism \\
\hline Secundum defect & Anomalies of the great arteries & Sub acute stenosis & Idiocy \\
\hline Inferior sinus venous defect & abnormal semilunar valves & Pulmonary stenosis & Holoprocencephaly \\
\hline Prium defect, & Endocardial fibrosis & Dextrocardia & Achondroplasia \\
\hline Doubly committed subarterial defects & $\begin{array}{l}\text { defects in pulmonary venus } \\
\text { drainage }\end{array}$ & Single ventricle & Hirschsprung disease \\
\hline Double outlet ventricles & Left ventricular hypertrophy & Common atrial trunk & Laterality defects \\
\hline $\begin{array}{l}\text { Truncus arteriosus, hearts with } \\
\text { univetriculr-atrioventriculr connection }\end{array}$ & Pulmonary arterial stenoses & Triatrial heart & Piebaldism \\
\hline $\begin{array}{l}\text { Sponatenous closure or demunition in } \\
\text { size of ventricular septal defect }\end{array}$ & Absent pulmonary valves & Tricusois atrasia & Werner syndrome \\
\hline $\begin{array}{l}\text { Mitral regurgitation, left atrial } \\
\text { obstruction }\end{array}$ & Abnormal right ventricle & Tricuspid valve diplysia & Bethlem myopathy \\
\hline Abnormal semilunar valves. & Corrected transposition & Transposition & Holt-oram syndrome \\
\hline defects with pulmonary hypertension, & Ventricular septal defect & Tricuspid atresia, & Cutis laxa \\
\hline $\begin{array}{l}\text { Acyanotic congenital heart disease in } \\
\text { adults }\end{array}$ & Tricuspid atresia & Endomyocardial fibrosis & Congenital adrenal hyperplasia \\
\hline Right ventricular (RV) failure & Double out flow right ventricle & Ebsteins anomaly & Usher's syndrome \\
\hline
\end{tabular}




\section{Biomarkers}

\section{Hemodynamic or cardiac biomarkers or blood bio- markers}

Most congenital heart diseases have specific hemodynamics, including volume and pressure overload. However, by using cardiac biomarkers cyanosis and pulmonary hypertension, associated with anatomical abnormalities can be established. Hemodynamic abnormalities can cause activation of neuro hormones, inflammatory cytokines, fibroblasts, and vascular endothelial cells, which in turn contribute to the development of pathological conditions such as cardiac hypertrophy, fibrosis, and cardiac cell damages and death. Cardiac biomarkers facilitate the prediction of pathological changes that could provide information about the stress placed on the myocardial cells, the severity of the damage, the responses of neuro humoral factors, and the remodeling of the ventricle (Table 2). Moreover, assessment of cardiac biomarkers at an earlier stage can reduce the myocardial damage and severity of heart failure. ${ }^{11}$ Therefore, children with CHD need most appropriate and delicate care $^{12}$ (Table 2).

Table 2 Important emerging biomarkers of congenital heart diseases and disorders

\begin{tabular}{|c|c|c|c|c|}
\hline Biomarker & Abnormality identified & Overall cases & Health problems & $\begin{array}{l}\text { Incidence } \\
\text { rate }\end{array}$ \\
\hline \multirow[t]{3}{*}{$\begin{array}{l}\text { Physiological } \\
\text { Biomarkers }\end{array}$} & $\begin{array}{l}\text { Intravenous ionotropic } \\
\text { infusions, Slow metabolic rate, } \\
\text { hyperkalemia }\end{array}$ & $E F<35 \%$ & CRP, NT-proBNP, maternal CRP, cord troponin I & Higher \\
\hline & $\begin{array}{l}\text { Anatomical anomalies, low } \\
\text { oxygenation and ventilation } \\
\text { of blood, lung or pulmonary } \\
\text { function, cardiac output, } \\
\text { sudden heart failures, abnormal } \\
\text { coagulation, cleft lip/palate, } \\
\text { Spina bifida aperta, Anencephaly }\end{array}$ & Overall $\mathrm{EF}<30 \%$ & $\begin{array}{l}\text { Blood pressure, Left atrial pressure, Heart rate, Pulmonary } \\
\text { artery pressure, Central venous pressure, Cardiac output, } \\
\text { Urine output, Chest tube out put }\end{array}$ & Moderate \\
\hline & $\begin{array}{l}\text { Respiratory distress, mitral } \\
\text { valve defects, left ventricular } \\
\text { dysfunctions }\end{array}$ & & Serum--myocardial fraction of creatine kinase, galectin-3 & Higher \\
\hline \multirow{6}{*}{$\begin{array}{l}\text { Hemodynamic } \\
\text { Biomarkers }\end{array}$} & Oxygenation & & B-type natriuretic peptide C-reactive protein levels & Higher \\
\hline & $\begin{array}{l}\text { Cardiac dysfunction, Myocardial } \\
\text { injury, Cardiac functional status }\end{array}$ & & $\begin{array}{l}\text { Plasma levels of NT-proBNP and NGAL, fasting glucose, } \\
\text { insulin , serum creatinine }\end{array}$ & Higher \\
\hline & Pulmonary arterial dysfunction & & C-reactive protein (CRP), & Higher \\
\hline & Inflammation, Cyanosis & & $\begin{array}{l}\text { Troponin I, Matrix metalloproteinase, urokinase, plasminogen } \\
\text { activator receptor, vitamin D }\end{array}$ & Higher \\
\hline & Fibrosis & & MMP-2 and uPA/uPAR & Higher \\
\hline & Acute kidney injury & & $\begin{array}{l}\text { Level of serum cystatin } \mathrm{C}(\mathrm{Cys} C), \mathrm{sCY} \mathrm{s} C \text {, uNGAL, uL-FABP, } \\
\text { troponin hsTnT level }\end{array}$ & Higher \\
\hline $\begin{array}{l}\text { Genetic } \\
\text { Biomarkers }\end{array}$ & $\begin{array}{l}\text { Different types of syndromes } \\
\text { and malformations, trisomy-2I } \\
\text { (Down syndrome, Turners } \\
\text { syndrome ( } 45 X O), \text { Williams } \\
\text { syndrome (7q deletion) AVSD, } \\
\text { VSA, Fallots, CoA, As, Mitral } \\
\text { stenosis, Supravalvular As. }\end{array}$ & $E F<7.3-10 \%$ & $\begin{array}{l}\text { SNPs, family of disease genes, Karyotyping, autosomal } \\
\text { mutations, level of micro RNAs, snRNPs, }\end{array}$ & Higher \\
\hline
\end{tabular}


Table Continued.

\begin{tabular}{llll}
\hline Biomarker & Abnormality identified & Overall cases & Health problems \\
\hline $\begin{array}{l}\text { Immunological } \\
\text { Biomarkers }\end{array}$ & $\begin{array}{l}\text { Loss of function, low immune } \\
\text { tolerance and self defense, }\end{array}$ & EF $>4 \%$ & Anti-Ro/SSA-p200, interleukin-6,VEGF, ICMA-I
\end{tabular}

\section{$\begin{array}{ll}\text { Biomarkers } & \text { tolerance and self defense, } \\ \text { idiopathic cardiac arrhythmias }\end{array}$}

Level of circulating miRNA, microRNAs and IncRNAs, expression profiles, Phenotype-genotype correlations, microdeletions, mitochondrial mutations, unstable expanding

Molecular

Biomarkers

Cardiac infaraction and end stage heart failure, aortic

$E F<6-11 \%$ aneurysm

Ebstein anomaly

Diagnostic

Biomarkers valve stenosis

Normal heart-lung-brain

function, Immediate and delayed immune defects, breathing and

Clinical Biomarkers and chance effect, non-coding mRNA, segmental aneuploidy, gene mapping and loci susceptibility, DNA finger printing using minisatellite probes, , DNA microarrays and functional defects in

Analysis of infectious proteins, defective proteins/factors, isotope coded affinity tags, establishment of disease and disorder state from normal

Very high heart valves, fibres, cardiac contraction, filling and pulsation

\section{Physiological markers}

Measurement of HDL-C(High-density lipoprotein cholesterol), Interleukin (IL-6, 10), 6-hydroxymelatonin, galectin-3 and plasma B-type natriuretic peptide low-density lipoprotein cholesterol levels, ischaemic stress and reactive oxygen species, folic acid, vitamin B12 are potential physiological biomarkers which can predict the risk of congenital heart diseases. ${ }^{12}$ These are also based on levels of homocysteine, hydrogen sulfide, and C-reactive protein in serum samples of children, In addition, atrio-ventricular and cardiac muscle contraction, ionic interaction and troponin activity are also important physiological markers. Similarly, risk prediction algorithms and vascular risk prediction rules and statistical scores can assess the risk of death or stroke in patients with atrial fibrillation and early age atherosclerosis. Further, oxygen transport between patients with restrictive right ventricle and those without right ventricle decides CHD in children ${ }^{13}$ Serum kinetics in children is also used to identify atrial and ventricular septal defects closure in terms of extracorporeal circulation. C-reactive protein demonstrates functional status of cardiac muscle functional status. Its level can predict clinical outcome and mortality in adults with pulmonary arterial hypertension associated with congenital heart disease. Single CRP assessment is also used to diagnose antibiotics abuse ${ }^{14}$ and find out significant differences between cyanotic and acyanotic congenital heart disease patients (Table 2). Children with CHD have shown elevated levels of inflammatory cytokines, caspase 3 , troponin $\mathrm{T}$, and $\mathrm{CKMB}$ which also display cardiac health or abnormality. However, by measuring tumor necrosis factor (TNF- $\alpha$ ), interleukin-6 (IL-6), vasoendothelial growth factor, troponin T, creatin kinase $\mathrm{MB}$, and Caspase 3 levels congenital defects can be established in children. ${ }^{15}$ In addition troponin I; matrix metalloproteinase-2; urokinase plasminogen activator; urokinase

plasminogen activator receptor; plasminogen; and vitamin D in body fluids can establish CHD related inflammation, fibrosis and cardiac dysfunction. ${ }^{16}$

For routine coronary heart disease (CHD) risk assessment serum biomarker specifically associated and based on baseline level of triglycerides, total cholesterol, low-density lipoprotein cholesterol, high-density lipoprotein cholesterol (HDL-C), body mass index, albumin, geriatric nutritional risk index, normalized protein catabolic rate, interleukin-6 (IL-6) and tumor necrosis factor- $\alpha$ (TNF- $\alpha$ ) are used. Following CRP and NT-proBNP levels after birth can potentially monitor severity and progression of cardiac neonatal lupus. ${ }^{16}$ Similarly, plasma C-terminal fibrinogen growth factor 23, fasting glucose and insulin level with high-sensitivity C-reactive protein recognize birth related vascular defects in children (Table 2) ${ }^{17}$ Baseline hemoglobin A1c level can accurately predict heart failures due to baseline cardiac structural and functional abnormalities. Right heart dysfunction, endothelial inflammation and proliferation can be diagnosed by measuring plasma levels. Similarly, plasma BNP measurements can differentiate congenital heart disease and lung disease and can be used to monitor the effects of treatment for infants with heart failure. ${ }^{18}$

Serum--myocardial fraction of creatine kinase and galectin-3 is used as biochemical marker for finding myocardial injury. However, increased serum concentration can help to find out clinical and paraclinical requirement of CHD children. ${ }^{19}$ Similarly, Cystatin C and serum creatinine level is used to establish acute kidney injury in children with congenital heart disease. ${ }^{2}$ Cystatin $\mathrm{C}$ is a better glomerular filtration rate marker than serum creatinine. ${ }^{20}$ Moreover, association of cardiac biomarkers (N-type pro-B-type natriuretic peptide, creatine kinase-MB, heart-type fatty acid binding protein, and troponins I and $\mathrm{T}$ can also diagnose postoperative AKI. ${ }^{21}$ 
However, level of certain mediators of neuro hormonal activation such as B-type natriuretic peptide and its N-terminal-pro-fragment, and vascular endothelial growth factor are used for diagnosing pulmonary arterial hypertension (PAH) in patients with congenital heart disease. Acute phase proteins, haptoglobin, SAP, and orosomucoid 2 change display Ventricular septal defect patients show intra-cardiac left-toright shunt and increased pulmonary flow that may affect the acute phase response. ${ }^{22}$ High-sensitive troponin-T is used for diagnosing acute coronary syndrome, in congenital heart disease patients and to display myocardial damage related to NT-proBNP and ventricular function, its potential predictive value in ACHD patients is promising. ${ }^{23}$ Similarly, lower levels of plasma NGAL differentiate patients with complex congenital heart disease and cyanotic congenital heart disease. Similarly, combined prognostic value of plasma NGAL with plasma NT-proBNP in adult patients can predict congenital heart disease ${ }^{24}$ and cardiovascular deaths. ${ }^{25}$ Differential metabolic components (blood pressures) and metabolic pathway network can be used as potential biomarkers for hypertension. ${ }^{26}$ Surfactant protein B plasma levels may help to diagnose patients with cardiac problems diminishing the alveolocapillary membrane stability (Table 2). More specifically, plasma levels can be measured in the preoperative and postoperative periods. ${ }^{24}$

\section{Genetic markers}

Genetic biomarkers are DNA sequences in gene which are responsible for disease or associated with susceptibility to disease. SNPs (single nucleotide polymorphisms) demonstrate significant variations among genes and are used to find risk stratification for ventricular arrhythmias in survivors of acute coronary syndromes and arrhythmic events after ACS (antireticularcytotoxic serum). ${ }^{27}$ Similarly, differential expression of HUB genes i.e. UBC, APP, HUWE1 and SRC display both congenital disorders and congenital heart defects in newborns (CHD) and are established genetic markers. ${ }^{4}$ Similarly, sequencing of important neonatal genes and its expression in tissues can help in identification of cardiac disorders (both syndromic and nonsyndromic disorders). ${ }^{28}$ Similarly, abnormal karyotype can work as good marker for establishing fetal congenital heart disease during pregnancy. More functional genetic markers are copy number variations, single gene mutations or single nucleotide polymorphisms are responsible for the development of $\mathrm{CHD}^{28}$ Aneuploidy, or abnormal chromosomal number, is also one of the important reasons of CHD. Normally, most of the CHD cases were observed in new born associating with some chromosomal abnormality. ${ }^{29}$ Fifty percent of cases born with Trisomy 21 have CHD mainly displaying either atrial or ventricular septal defects to atrioventricular canal lesions. Similarly, Trisomy 18, bear CHD, more usually in the form of septal defects. Approximately one-third of females with Turner syndrome, or monosomy X, have CHD. Approximately one-third of females with Turner syndrome, or monosomy X, have CHD. In such cases chromosomal defects in patients with CHD can be detected by using chromosomal G-banded karyotype. Klinefelter syndrome males who display 47 chromosomes (XXY), showed fifty percent incidences of CHD i.e ductus arteriosus and atrial septal defects. ${ }^{29}$ However, different types of chromosomal abnormalities can be established by using fluorescence in situ hybridization (FISH). In this technique fluorescent labeled probes are hybridized to study metaphase chromosomes to detect small submicroscopic chromosomal deletions and duplications. FISH technique is used to establish cause of several syndromes caused by chromosomal abnormalities and associating with CHDs. Microscopic deletion on chromosome can reveal fact about occurrence of most common cardiac malformations such as interrupted aortic arch, truncus arteriosus, and tetralogy of Fallot, and routine with genetic testing. ${ }^{30}$ The cardio-vascular defects due to any syndrome can be traced by identifying loss of elastin due to mutations that causes supravalvar aortic stenosis..$^{31,32}$ Similar abnormalities can be identified by measuring alpha II-spectrin breakdown products in the serum..$^{33}$ Non-coding RNA (ncRNAs) is emerging as new fundamental regulators of gene expression (Table 2). microRNAs and lncRNAs work as clinical biomarkers for aortic aneurysm. ${ }^{7}$

\section{Immunological biomarkers}

Interleukin-6, $174 \mathrm{GC}$ polymorphism and C-reactive protein can recognize idiopathic cardiac arrhythmias in children. ${ }^{34}$ Similarly, ratio between specific anti-52 Ro/SSA-p200 antibodies displays congenital heart block. ${ }^{35}$ It is used to identify mothers at higher risk to deliver affected children. ICAM-1 is a potential biomarker to be used for the diagnosis and follow-up of pulmonary artery hypertension (Table 2) ${ }^{36}$ Other important immunological biomarkers which could provide better specificity about CHD are levels of different cytokines, chemokines, circulating antigens, antibodies in serum and constitutively expressed natural auto antibodies (na-Ab) which interact specifically with different self-antigens and plurality of anti-self receptors of auto reactive T-lymphocytes.

\section{Molecular markers}

Molecular biomarkers based on presence of circulating miRNA expression profilesare used to predict congenital heart diseases mainly for clinical diagnosis of pulmonary arterial hypertension associated abnormalities. ${ }^{37}$ Congenital heart disease patients show high levels of natriuretic peptide (NP) in comparison to normal controls. Similarly, levels of norepinephrine found altered in symptomatic patients, especially those with unrepaired congenital heart disease, Eisenmenger syndrome, pulmonary hypertension and adult congenital heart failure. ${ }^{38}$ These are used as, molecular markers for prediction of congenital heart disease. ${ }^{39}$ Similarly, level ofTBX5 a transcription factor diagnose embryonic cardiac defects. ${ }^{40}$ Its 2.77 and 3.51 times higher levels of miR-10a and miR-10b expression in the heart tissues display congenital heart diseases. Similarly, levels of -fatty acid-binding protein, N-terminal pro-brain natriuretic peptide (NT-proBNP), and $\mathrm{cTnI}^{41}$ are also used to recognize heart function. Similarly, B-type natriuretic peptide monitoring identifies patients with cyanosis at increased risk of an augmented inflammatory response to cardiopulmonary bypass. Insulin-like growth factor-binding protein 7 and tissue inhibitor of metalloproteinases-2 which induce G1 cell cycle arrest used as biomarkers for AKI and cardiopulmonary bypass. ${ }^{42}$ Growth hormone and its mediator, insulin like growth factor 1 , are key determinants of growth in children and young adults. It can also identify other forms of congenital heart disease (Table 2) ${ }^{43}$

\section{Diagnostic biomarkers}

Flow cytometry, ${ }^{44}$ cardiac magnetic resonance, ${ }^{45}$ and echocardiographic are is used as diagnostic tool for finding defects in both the right and the left heart. Echocardiographic is also used to detect pediatric PAH that can be correlated both at presentation and during the course of the disease. ${ }^{46}$ Renal near-infrared spectroscopy NIRS is a promising non-invasive tool that is used for multimodal monitoring of kidney function and developing AKI in infants undergoing cardiac surgery with cardiopulmonary bypass. ${ }^{46}$ Apolipoprotein E plays 
critical role in modulating the response to neurological injury after cardiopulmonary bypass in children. ${ }^{47}$ Transcatheter aortic valve implantation is becoming a standard treatment for non-operable and high-risk patients with symptomatic severe aortic valve stenosis (Table 2).$^{48}$ Electroencephalography or magneto encephalography or volumetric measures of certain brain regions by using magnetic resonance imaging provide both accuracy and specificity and clarity about brain related abnormalities in children and adults.

\section{Therapeutic biomarkers}

Therapeutic biomarkers could establish specific interaction of drugs to heart diseases or find abnormalities related to biomolecules and cells of cardiac system. MicroRNAs (miRs) a small, highly conserved, non-coding RNAs can be used as important therapeutic biomarkers. Similarly, long-term use of pravastatin, simvastatin, atorvastatin, or rosuvastatin, statins, may be effective in the primary and secondary prevention of cardiovascular events through an antiinflammatory effect, Prostaglandin E1 has been used clinically for improving heart diseases. Similarly high-risk patients can be treated with lipid-lowering agents to have a normal LDL-C level. Lycopene intake reduces the incidence of CVD. Measurement of $L p(a)$ for risk assessment of patients with known CHD. $\alpha$-linolenic acid (ALA), a plant-derived omega-3 (n-3) fatty acid and 3-hydroxy-3methylglutaryl-CoA (HMG-CoA) reductase are important therapeutic biomarker. Similarly, atorvastatin improved plasma levels of an expanded panel of nonlipid biomarkers.

The pulmonary homograft is used to remove congenital aortic stenosis by following. Serum levels of soluble ICAM-1 can provide confirmation about pulmonary artery hypertension in children. ${ }^{36}$ Similarly, total right/left-volume index should be used as a new and simplified CMR measure, allowing more accurate assessment of disease severity ${ }^{44}$ Echocardiography and Fontan surgery are used to assess the systemic right ventricle problems in patients with repaired tetralogy of Fallot. There is a need to have many more researches on development of new advanced management tools are finding risk stratification and understanding the role of novel biomarkers related to surgical treatments (Table 2).

\section{Clinical biomarkers}

WBCs, polymorphonuclear cell counts are used as clinical biomarkers to detect cardiopulmonary problems. Similarly, plasma intestinal fatty acid-binding protein, citrulline, claudin 3, and dual sugar permeability, intestinal epithelial integrity, epithelial function, paracellular integrity, and paracellular functions, loss of intestinal epithelial barrier function are used to display primary congenital heart defects. However, by measuring baseline plasma proinflammatory (interleukin-6, tumor necrosis factor- $\alpha$, and interferon- $\gamma$ ) and anti-inflammatory (interleukin-4 and interleukin-10) cytokines, cardiopulmonary problems can be identified. Plasma biomarkers are used to reflect intestinal epithelial barrier function (cellular and paracellular) in cardiopulmonary defects. ${ }^{49}$ Erythropoietin functional activity determination help in assessment of in vitro pulmonary artery endothelial cell networking and smooth muscle cell proliferation assays (Table 2). Serum spectrin breakdown products may potentially be developed as biomarkers for brain necrosis and apoptosis in infants with congenital heart disease. Prenatal diagnosis of neural defects can be done in utero by measuring alpha fetoprotein. Ultrasound is used to visualize the defects in fetus while amniocentesis is used to detect teratogenic defects. Level of serum uric acid and pituitary and thyroid hormone are used to find malformations are also related to reproductive failures in adults.

More functional genetic markers are copy number variations, single gene mutations or single nucleotide polymorphisms are responsible for the development of CHD. ${ }^{28}$ Aneuploidy, or abnormal chromosomal number, is also one of the important reasons of CHD. Normally, most of the CHD cases were observed in new born associating with some chromosomal abnormality. ${ }^{29}$ Fifty percent of cases born with Trisomy 21 have CHD mainly displaying either atrial or ventricular septal defects to atrioventricular canal lesions. Similarly, Trisomy 18, bear CHD, more usually in the form of septal defects. Approximately one-third of females with Turner syndrome, or monosomy X, have CHD. Approximately one-third of females with Turner syndrome, or monosomy X, have CHD. In such cases chromosomal defects in patients with CHD can be detected by using chromosomal G-banded karyotype. Klinefelter syndrome males who display 47 chromosomes (XXY), showed fifty percent incidences of CHD i.e ductus arteriosus and atrial septal defects. ${ }^{29}$ However, different types of chromosomal abnormalities can be established by using fluorescence in situ hybridization (FISH). In this technique fluorescent labeled probes are hybridized to study metaphase chromosomes to detect small submicroscopic chromosomal deletions and duplications. FISH technique is used to establish cause of several syndromes caused by chromosomal abnormalities and associating with CHDs. Microscopic deletion on chromosome can reveal fact about occurrence of most common cardiac malformations such as interrupted aortic arch, truncus arteriosus, and tetralogy of Fallot, and routine with genetic testing. ${ }^{30}$ The cardio-vascular defects due to any syndrome can be traced by identifying loss of elastin due to mutations that causes supravalvar aortic stenosis. ${ }^{31,32}$ Similar abnormalities can be identified by measuring alpha II-spectrin breakdown products in the serum..$^{33}$ Non-coding RNA (ncRNAs) is emerging as new fundamental regulators of gene expression (Table 2). microRNAs and lncRNAs work as clinical biomarkers for aortic aneurysm. ${ }^{7}$

\section{Future developments}

For finding better diagnostic and therapeutic care of CHD patients technological advancements be needed in the field of functional genomics, proteomics, metabolomics, and bioinformatics to have new putative markers to decide various abnormal stages of congenital disorders. Thus multimarker profiling of CHD individuals based on real variations may focus on more possible treatment and clinical care in the future. In addition, epigenetic effects of series of environmental carcinogens in human population in industrialized countries resulting in prenatal and post natal defects of cardiac structure and function in early stage children can be explored.

\section{Conclusion}

For better clinical care of CHD patients and diagnosis there is a need of systematic organization of tools, methods, rules, strategies, medical diagnostic information with coordinated and concerted efforts of clinicians, research groups, technology experts, industry and regulatory agencies. Both standardization and technological advancement of existing diagnostic and therapeutic methods is needed for reduction of congenital heart disease risks related to heart failure In addition, risk prediction algorithms should develop, and standardize to incorporate select biomarkers that could enable clinicians to predict the absolute event rates of CHD. As emerging risks are found to be affiliated with minor and micro-level factors and 
its diagnosis at an earlier stage is still undecided in most of the cases to find mixed CHDs. Hence, there is an urgent need of exploration of new emerging biomarkers that could facilitate more authentic and fast diagnosis of congenital heart failures and various structural and physiological abnormalities and disorders in the future.

\section{Acknowledgements}

None.

\section{Conflict of interest}

The author declares no conflict of interest.

\section{References}

1. Yan L, Ge Q, Xi C, et al. Genetic variations of VEGF gene were associated with tetralogy of fallot risk in a chinese han population. Genet Test Mol Biomarkers. 2011;9(5):264-271.

2. Petrovic S, Bogavac Stanojevic N, Lakic D, et al. Cost-effectiveness analysis of acute kidney injury biomarkers in pediatric cardiac surgery. Biochem Med (Zagreb). 2015;25(2):262-271.

3. Mirabella L, Barker AJ, Saikrishnan N, et al. MRI-based protocol to characterize the relationship between bicuspid aortic valve morphology and hemodynamics. Ann Biomed Eng. 2015;43(8):1815-1827.

4. Yu S, Yi H, Wang Z, et al. Screening key genes associated with congenital heart defects in Down syndrome based on differential expression network. Int J Clin Exp Pathol. 2015;8(7):8385-8393.

5. Xu X, Friehs I, Zhong Hu T, et al. Endocardial fibroelastosis is caused by aberrant endothelial to mesenchymal transition. Circ Res. 2015;116(5):857-866

6. Blok IM, Van Riel AC, Mulder BJ, et al. Management of patients with pulmonary arterial hypertension due to congenital heart disease: recent advances and future directions. Expert Rev Cardiovasc Ther. 2015;16:1-16.

7. Duggirala A, Delogu F, Angelini TG, et al. Non coding RNAs in aortic aneurysmal disease. Front Genet. 2015;6:125.

8. LeMond L, Mai T, Broberg CS, et al. Heart failure in adult congenital heart disease: nonpharmacologic treatment strategies. Cardiol Clin. 2015;33(4):589-598.

9. Nawaytou H, Bernstein HS. Biomarkers in pediatric heart disease. Biomark Med. 2014;8(7):943-963.

10. Dobson R, Walker HA, Walker NL. Biomarkers in congenital heart disease. Biomark Med. 2014;8(7):965-75.

11. Sugimoto M, Kuwata S, Kurishima C, et al. Cardiac biomarkers in children with congenital heart disease. World J Pediatr. 2015;11(4):309315.

12. Sun L, Sun S, Li Y, et al. Potential biomarkers predicting risk of pulmonary hypertension in congenital heart disease: the role of homocysteine and hydrogen sulfide. Chin Med J (Engl). 2014;127(5):893-899.

13. Xu Z, Zhang M, Zhu L, et al. Elevated plasma B-type natriuretic peptide and $\mathrm{C}$-reactive protein levels in children with restrictive right ventricular physiology following tetralogy of Fallot repair. Congenit Heart Dis. 2014;9(6):521-528.

14. Jaworski R, Haponiuk I, Irga Jaworska N, et al. Kinetics of C-reactive protein in children with congenital heart diseases in the early period after cardiosurgical treatment with extracorporeal circulation. Adv Med Sci. 2014;59(1):19-22.

15. Nassef YE, Hanan F Aly, Manal A Hamed. Inflammatory cytokines, apoptotic, tissue injury and remodeling biomarkers in children withcongenital heart disease. Indian J Clin Biochem. 2014;29(2):145-149.
16. Saxena A, Izmirly PM, Han SW, et al. Serum biomarkers of inflammation, fibrosis, and cardiac function in facilitating diagnosis, prognosis, and treatment of anti-ssa/ro-associated cardiac neonatal lupus. $\mathrm{J} \mathrm{Am}$ Coll Cardiol. 2015;66(8):930-939.

17. Karamanian VA, Harhay M, Grant GR, et al. Erythropoietin upregulation in pulmonary arterial hypertension. Pulm Circ. 2014;4(2):269-279.

18. Sahingozlu T, Karadas U, Eliacik K, et al. Brain natriuretic peptide: the reason of respiratory distress is heart disease or lung disease? Am J Emerg Med. 2015;33(5):697-700.

19. Dudnyk VM, Zborovskaya OO. Biochemical markers of myocardial in children after surgical correction of congenital heart disease. Lik Sprava. 2015;(1-2):127-9.

20. Zappitelli M, Greenberg JH, Coca SG, et al. Association of definition of acute kidney injury by cystatin $\mathrm{C}$ rise with biomarkers and clinical outcomes in children undergoing cardiac surgery. JAMA Pediatr. 2015;169(6):583-591.

21. Bucholz EM, Whitlock RP, Zappitelli M, et al. Cardiac biomarkers and acute kidney injury after cardiac surgery. Pediatrics. 2015;135(4):945956.

22. Zhang $\mathrm{X}$, Wang $\mathrm{K}$, Yang $\mathrm{Q}$, et al. Acute phase proteins altered in the plasma of patients with congenital ventricular septal defect. Proteomics Clin Appl. 2015;9(11-12):1087-1096.

23. Eindhoven JA, Roos Hesselink JW, Van den Bosch AE, et al. Highsensitive troponin-T in adult congenital heart disease. Int J Cardiol. 2015;184:405-411.

24. IsiK O, Disli OM, Bas T, et al. High postoperative serum levels of surfactant type B as novel prognostic markers for congenitalheart surgery. Rev Bras Cir Cardiovasc. 2014;29(2):186-191.

25. Frogoudaki A, Andreou C, Parissis J, et al. Clinical and prognostic implications of plasma NGAL and NT-proBNP in adult patients withcongenital heart disease. Int J Cardiol. 2014;177(3):1026-1030.

26. Zhong L, Zhang JP, Nuermaimaiti AG, et al. Study on plasmatic metabolomics of Uygur patients with essential hypertension based on nuclear magnetic resonance technique. Eur Rev Med Pharmacol Sci. 2014;18(23):3673-3680.

27. Earle NJ, Poppe KK, Pilbrow AP, et al. Genetic markers of repolarization and arrhythmic events after acute coronary syndromes. Am Heart J. 2015;169(4):579-586.

28. Lebo MS, Baxter SM. New molecular genetic tests in the diagnosis of heart disease. Clin Lab Med. 2014;34(1):137-156.

29. Pierpont ME, Basson CT, Benson DW, et al. Genetic basis for congenital heart defects: current knowledge: a scientific statement from the american heart association congenital cardiac defects committee, council on cardiovascular disease in the young: endorsed by the american academy of pediatrics. Circulation. 2007;115(23):3015-3038.

30. Goldmuntz E, Clark BJ, Mitchell LE, et al. Frequency of $22 \mathrm{q} 11$ deletions in patients with conotruncal defects. $J$ Am Coll Cardiol. 1998;32(2):492-498.

31. Ewart AK, Jin W, Atkinson D, et al. Supravalvular aortic stenosis associated with a deletion disrupting the elastin gene. J Clin Invest. 1994;93(3):1071-1077.

32. Li DY, Toland AE, Boak BB, et al. Elastin point mutations cause an obstructive vascular disease, supravalvular aortic stenosis. Hum Mol Genet. 1997;6(7):1021-1028.

33. Jain P, Spaeder MC, Donofrio MT, et al. Detection of alpha II-spectrin breakdown products in the serum of neonates with congenital heart disease*. Pediatr Crit Care Med. 2014;15(3):229-235. 
34. Szydlowski L. The role of Interleukin-6, its $-174 \mathrm{G}>\mathrm{C}$ polymorphism and $\mathrm{C}$-reactive protein in idiopathic cardiac arrhythmias in children. Adv Med Sci. 2013;58(2):320-325.

35. Scarsi M, Radice A, Pregnolato F, et al. Anti-Ro/SSA-p200 antibodies in the prediction of congenital heart block. An Italian multicentre cross-sectional study on behalf of the 'forum interdisciplinare per la ricerca nelle malattie autoimmuni (FIRMA) group'. Clin Exp Rheumatol. 2014;32(6):848-854.

36. Oguz MM, Oguz AD, Sanli C, et al. Serum levels of soluble ICAM-1 in children with pulmonary artery hypertension. Tex Heart Inst J. 2014;41(2):159-164.

37. Niu Y, Limin Z, Huiling Q, et al. An improved method for detecting circulating micro RNAs with S-Poly(T) Plus real-time PCR. Sci Rep. $2015 ; 5: 15100$

38. Ohuchi H, Diller GP. Biomarkers in adult congenital heart disease heart failure. Heart Fail Clin. 2014;10(1):43-56.

39. Wang F, Yang XY, Zhao JY, et al. miR-10a and miR-10b target the 3'untranslated region of TBX5 to repress its expression. Pediatr Cardiol. 2014;35(6):1072-1079

40. Zhou FJ, Zhou CY, Tian YJ, et al. Diagnostic value of analysis of HFABP, NT-proBNP, and cTnI in heart function in children withcongenital heart disease and pneumonia. Eur Rev Med Pharmacol Sci. 2014;18(10):1513-1516.

41. Meersch M, Schmidt C, Van Aken H, et al. Validation of cell-cycle arrest biomarkers for acute kidney injury after pediatric cardiac surgery. PLoS One. 2014;9(10):110865.

42. Avitabile CM, Leonard MB, Brodsky JL, et al. Usefulness of insulin like growth factor 1 as a marker of heart failure in children and young adults after the Fontan palliation procedure. Am J Cardiol. 2015;115(6):816820.
43. Subbotovskaia AI, Krivoshapkina AA, Shilova AN, et al. The flow cytometry in diagnostic of sepsis in children of first year of life with congenital heart disease and operated in conditions of artificial circulation. Klin Lab Diagn. 2014;59(7):17-20.

44. Hosch O, Sohns JM, Nguyen TT, et al. The total right/left-volume index: a new and simplified cardiac magnetic resonance measure to evaluate the severity of Ebstein anomaly of the tricuspid valve: a comparison with heart failure markers from various modalities. Circ Cardiovasc Imaging. 2014;7(4):601-609.

45. Ploegstra MJ, Roofthooft MT, Douwes JM, et al. Echocardiography in pediatric pulmonary arterial hypertension: early study on assessing diseaseseverity and predicting outcome. Circ Cardiovasc Imaging. 2014;8(1):pii:e000878.

46. Ruf B, Bonelli V, Balling G, et al. Intraoperative renal near-infrared spectroscopy indicates developing acute kidney injury in infants undergoing cardiac surgery with cardiopulmonary bypass: a case-control study. Crit Care. 2015;19:27.

47. Agirbasli M, Song J, Lei F, et al. Apolipoprotein E levels in pediatric patients undergoing cardiopulmonary bypass. Artif Organs. 2015;39(1):28-33.

48. Van der Bom T, Winter MM, Knaake JL, et al. Long-term benefits of exercise training in patients with a systemic right ventricle. Int $J$ Cardiol. 2015;179:105-111.

49. Typpo KV, Larmonier CB, Deschenes J, et al. Clinical characteristics associated with postoperative intestinal epithelial barrier dysfunction in children with congenital heart disease. Pediatr Crit Care Med. 2015;16(1):37-44 